\title{
Long-term prophylactic insulin treatment can prevent spontaneous diabetes and thyroiditis development in the diabetes-prone bio-breeding rat, while short-term treatment is ineffective
}

\author{
J Visser, F Klatter, L Vis, H Groen, J Strubbe ${ }^{1}$ and J Rozing \\ Department of Cell Biology, Immunology Section and ${ }^{1}$ Department of Animal Physiology, University of Groningen, The Netherlands \\ (Correspondence should be addressed to J Rozing, University of Groningen, Department of Cell Biology, Immunology Section, Building 3215, 11th Floor, \\ A Deusinglaan 1, 9713 AV Groningen, The Netherlands; Email: j.rozing@med.rug.nl)
}

\begin{abstract}
Objective: Prophylactic insulin treatment has been demonstrated to reduce diabetes development in the diabetes-prone bio-breeding (DP-BB) rat. These prophylactic insulin treatments were given from 50 to 150 days of age. However, several data indicate that the diabetogenic process in DP-BB rats starts well before day 50 .

Design and methods: DP-BB rats were given bovine insulin pellets from 21 to 60 days of age, from 21 to 100 days of age and from 60 to 100 days of age. At 160 days of age a glucose tolerance test was performed to establish $\beta$-cell function and pancreata collected for histological analysis.

Results: Prophylactic insulin treatment from 21 to 100 days of age gave a $42 \%$ reduction of diabetes incidence. The other treatment protocols had no effect. Non-diabetic rats treated with insulin from day 21 to 100 showed normal glucose tolerance and no sign of insulitis at 160 days of age. Non-diabetic rats of the control group and the other treatment groups showed normal glucose tolerance, but a slight increase of insulitis. Interestingly, the 21-100 day treated rats showed reduced serum levels of anti-colloid antibodies as compared with the control group.

Conclusions: These results show that short-term prophylactic insulin treatment cannot prevent diabetes and thyroiditis development in DP-BB rats. The prophylactic treatment must start well before 60 days of age and be prolonged into the phase when the rats normally become diabetic to reduce diabetes incidence. These findings imply that in the human situation prophylactic insulin treatment must be prolonged over the normal range of diabetes onset.
\end{abstract}

European Journal of Endocrinology $149223-229$

\section{Introduction}

The diabetes-prone bio-breeding (DP-BB) rat is a very useful animal model of human insulin-dependent diabetes mellitus (IDDM). Like the human situation, IDDM in the DP-BB rat is spontaneous and results in the autoimmune destruction of the insulin-producing $\beta$-cells of the pancreas (1).

Investigations into the etiology of IDDM suggest that both genetic and environmental factors are involved $(2,3)$. Important environmental factors in the development of human IDDM are diet and viral infections $(2-4)$.

DP-BB rats develop diabetes in a range from 60 to 120 days of age. This stage of disease development is characterized by severe insulitis (1). The islets of Langerhans are infiltrated by macrophages, natural killer cells and cytotoxic T cells leading to destruction of the $\beta$-cells (1). Cytokines, particularly the proinflammatory ones such as tumor necrosis factor (TNF) $\alpha$ and interleukin (IL)-1, are cytotoxic for $\beta$-cells and induce the inflammatory cascade leading to $\beta$-cell destruction $(5,6)$. Several reports show that increased expression of proinflammatory cytokines such as IL-12, TNF- $\alpha$, IL-1 and interferon- $\gamma$ is associated with $\beta$-cell destructive insulitis, whereas non-destructive insulitis is more associated with increased expression of anti-inflammatory type 2 cytokines such as IL- 10 and IL- 4 and the type 3 cytokine transforming growth factor- $\beta(6-8)$.

Prophylactic insulin treatment has been shown to be effective in the prevention of diabetes development in animal models of diabetes such as the NOD mouse and the BB rat (9). One of the mechanisms involved in this protection is the induction of $\beta$-cell rest, which causes a reduction of macrophage infiltration into the islets of Langerhans and subsequently less $\beta$-cell 
destruction $(9,10)$. Other mechanisms are the induction of immunological tolerance or reduction of the destructive autoimmune process by the induction of anti-inflammatory cytokines (9).

Gotfredsen et al. (11) were the first to demonstrate that life-long treatment with high doses of insulin could protect DP-BB rats against diabetes. In addition, Gottlieb et al. (12) demonstrated that only hypoglycemic doses of insulin could protect anti-RT6 treated diabetesresistant (DR)-BB rats from becoming diabetic, while lower doses were ineffective. In that study, activated spleen cells of protected DR-BB rats were still able to transfer diabetes, suggesting that the auto-reactive cell population is still present, but functionally dormant, in the treated animals (12). Taken together the experiments performed by Gotfredsen et al. and Gottlieb et al. suggest that in the DP-BB rat model of diabetes, protection by prophylactic insulin treatment works mainly via the induction of $\beta$-cell rest $(11,12)$.

The prophylactic insulin treatments in the DP-BB rat were given from 50 to 150 days of age, but several data indicate that the autoimmune diabetogenic process in DP-BB rats starts well before day 50 (1). For example, in the DP-BB rat model of diabetes, an early time interval has been identified in which diabetes can be prevented (1). Thymectomy of DP-BB rats around 30 days of age prevents IDDM, whereas thymectomy at day 60 has no effect (13). Accordingly, injection with regulatory $\mathrm{RT}^{+}{ }^{+} \mathrm{T}$ cells from DR-BB rats in the period from 21 to 60 days of age prevents diabetes in DP-BB rats, while injection from 60 to 100 days does not influence the disease (14). Moreover, timing of immunosuppressive therapy in the DP-BB rat is crucial for the prevention of type 1 diabetes (15). These findings indicate that the period between 21 and 60 days of age is critical for the development of diabetes in DP-BB rats and the autoimmune process can be stopped.

Interestingly, the beginning of this period starts with the moment of weaning of the rats. Weaning is associated with a dramatic change in metabolic activity of the animal. The rats change from mother's milk to solid food and have to increase their metabolic activity to keep warm and for growth. In this period the $\beta$-cells show a strong increase in number and activity (16). Active $\beta$-cells are shown to be more visible for the autoimmune response. Active $\beta$-cells are more immunogenic and produce monocyte chemoattractant protein (MCP)-1 and other chemokines (17-19). MCP-1 is a chemokine that attracts antigen-presenting cells like macrophages and dendritic cells and activated T cells (20). This means that in the period between 21 and 60 days, because of the increased activity of the $\beta$-cell and the rise of the autoimmune response, the $\mathrm{DP}-\mathrm{BB}$ rat is the most vulnerable for the development of IDDM. Inducing $\beta$-cell rest in this period might protect the DP-BB rats against diabetes development later in life.
For this purpose, we investigated whether a prophylactic insulin treatment in this period can influence diabetes development later in life as compared with a long-term insulin treatment. Moreover, we investigated whether a therapeutic window existed for prophylactic insulin treatment.

\section{Materials and methods}

\section{Animals}

DP-BB and DR-BB rats were kept under viral antibody free conditions in the Central Animal Facility of the University of Groningen and fed standard chow (Rodent Diet nr. Rmh-B2181; Hope Farms, Woerden, The Netherlands) and acidified water freely. In this study, rats from both sexes were used. In our colony over $85 \%$ of the DP-BB rats spontaneously develop diabetes before 130 days of age, with no gender differences.

All animals received humane care in compliance with the principles of laboratory animal care (NIH publication no. 85-23, revised 1985) and the Dutch law on experimental animal care.

\section{Experimental protocol}

In this study DP-BB rats were treated with bovine insulin pellets (implanted s.c., release $1.5-2 \mathrm{IU} / 24 \mathrm{~h}$ for 40 days; Linplant, Scarborough, Ontario, Canada) from 21 to 60 days of age, from 21 to 100 days of age and from 60 to 100 days of age. The dose (between 10 and $13.3 \mathrm{IU} / \mathrm{kg}$ body weight) supplied to the animals is comparable with the dosages used in the studies by Gottlieb et al. (11) and Gotfredsen et al. (12). At 160 days of age a glucose tolerance test was performed to establish $\beta$-cell function in the remaining non-diabetic rats and the pancreata were collected for histological analysis.

Rats were weighed three times a week and screened for hyperglycemia using blood glucose test strips (Roche Diagnostics, Almere, The Netherlands). A meter calculated the exact glucose concentration. The used strips had the advantage that if the meter should fail you always have a visual coloring of the strips allowing an estimation of the glucose concentration. Rats were diagnosed diabetic on the basis of a plasma glucose concentration $>11 \mathrm{mmol} / \mathrm{l}$ on two consecutive occasions. Diagnosis was confirmed by histological inspection of pancreatic tissue obtained at autopsy.

During the experiments none of the rats died of hypoglycemia. However, during a pilot experiment when we were testing the insulin pellets, three rats died because of hypoglycemia. This was due to the fact that the animal-housing facility forgot to feed these rats during the weekend. Therefore, we made sure that the rats included in this study received enough food and water during the experimental period. 


\section{Pancreas histology}

The degree of insulitis was calculated as described by Visser et al. (4, 15). Upon autopsy, the pancreas was removed, cleaned of fat and lymph nodes, fixed in Bouin's solution and processed for histological analysis. Sections (7 microns) were stained with hematoxylin and eosin for evaluation of macrophage/mononuclear cell infiltration (insulitis) and degree of islet damage using a Zeiss microscope. The degree of insulitis was rated on a scale of $1-4$ as follows: 1, normal islet appearance and no infiltration; 2, mild insulitis where macrophages/mononuclear cells are around, but not in the islets; 3 , severe insulitis, where macrophages/ mononuclear cells completely penetrate and infiltrate the islets; 4, end-stage islets. Per pancreas section an average histological insulitis score was calculated by adding up the histological insulitis score of each islet and dividing it by the total number of islets counted. Per section a minimum of five islets were counted, depending on the diabetes status of the animal; the number of islets per section ranged from 5 to 20. The analysis was performed independently by two persons.

\section{Glucose tolerance test}

After an overnight fast from food, rats were injected i.p. with $100 \mathrm{mg}$ glucose per $100 \mathrm{~g}$ body weight using a $200 \mathrm{mg} / \mathrm{ml}$ glucose solution in water. Blood was obtained by tail puncture just before and at 30, 60 and $120 \mathrm{~min}$ after the glucose injection.

\section{Detection of anti-colloid autoantibodies}

Anti-colloid antibodies in the serum were detected using the indirect immunofluorescence technique.

Six-micron thin frozen porcine thyroid sections were cut, air dried overnight and fixed in cold acetone $\left(-20^{\circ} \mathrm{C}\right)$ for $10 \mathrm{~min}$. The sections were preincubated with normal rabbit serum (Dako, Glostrup, Denmark) (diluted 50-fold in PBS with 1\% BSA) for $10 \mathrm{~min}$. The sections were incubated with several dilutions of the rat serum (rat sera were diluted in PBS as indicated in Table 2). After washing in PBS, the sections were incubated with FITC-labeled rabbit anti-rat immunoglobulins (Dako) diluted 25-fold in PBS/1\% BSA for $30 \mathrm{~min}$. After this second step the slides were washed in PBS and embedded in aquamount (Gurr, BDH limited, Poole, Dorset, UK) and examined using a fluorescence microscope. Three control slides were included: one without incubation of rat serum, another incubated with a serum previously scored as negative and one with a rat serum previously scored as positive. The staining intensity was arbitrarily and blindly scored by two independent persons as negative, positive, strong positive and very strong positive. The titer was set as the last dilution at which the serum scored positive.

\section{Statistical analysis}

The product limit method of Kaplan and Meier was used to estimate diabetes incidence. Diabetes incidences in the test groups at 160 days of age were compared using the chi-square test. The mean insulitis scores and the autoantibody titers of the groups were compared using the Mann-Whitney U test. We considered $P$ values less than 0.05 to be significant. For statistical analysis the SPSS 8.0 software package for Windows was used.

\section{Results}

\section{Short-term prophylactic insulin treatment has no effect on diabetes development, whereas a long-term insulin treatment gave a reduction of $42 \%$}

As shown in Fig. 1, short-term prophylactic insulin treatment from day 21 to 60 has no effect on the diabetes development later in life. The treatment has no effect on diabetes onset and the diabetes incidence.

When the pellets are no longer releasing insulin, the rats that have become diabetic between day 60 and 100 will show an increase in blood glucose levels. Indeed, around 100 days of age the first animals in the long-term treated group have blood glucose levels exceeding $11 \mathrm{mmol} / \mathrm{l}$. The slope of the curve of the long-term treated group is comparable with the slope of the curve from the control group. However, the

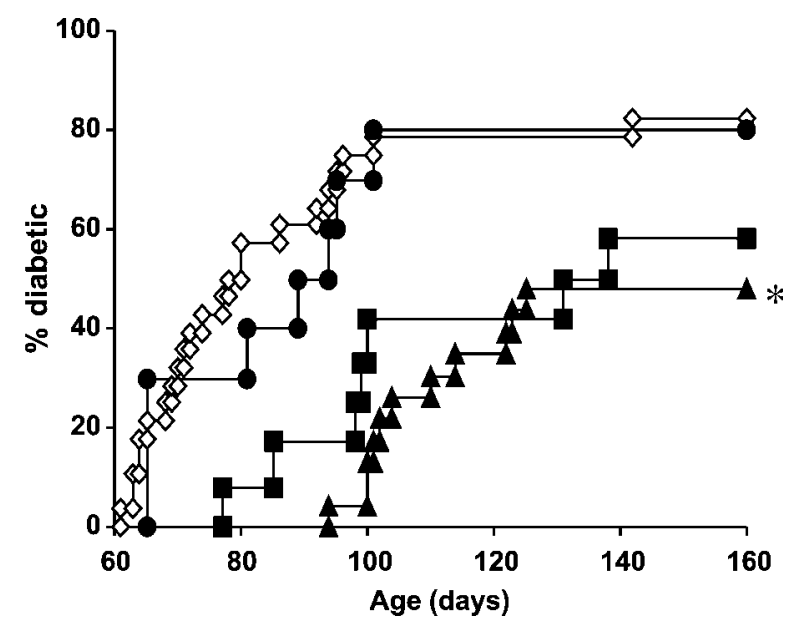

Figure 1 Long-term insulin treatment prevents diabetes development in DP-BB rats, whereas short-term treatment does not. DP-BB rats were treated with bovine insulin pellets (implanted s.c., release $1.5-2 \mathrm{IU} / 24 \mathrm{~h}$ for 40 days) from 21 to 60 days of age $(\bullet ; n=11)$, from 60 to 100 days of age $(\square ; n=12)$ and from 21 to 100 days of age $(\mathbf{\Lambda} ; n=23)$. The diabetes development was compared with control rats that received a placebo pellet $(\diamond ; n=23)$. At 160 days of age, significance of the difference in diabetes incidence was calculated using the chi-square test. ${ }^{\star} P<0.05$ as compared with the control group. 
insulin treatment from day 21 to 100 gives a reduction of approximately $42 \%$ in diabetes incidence at day 160 as compared with the control group $(P=0.01$, chi-square test). The rats that were treated with insulin from day 60 to 100 showed no reduction in diabetes development $(P=0.13$, chi-square test $)$.

\section{Animals on prophylactic insulin therapy display reduced blood glucose levels, but no severe hypoglycemia}

In view of the fact that insulin therapy can cause severe hypoglycemia, we monitored four rats treated with insulin from day 21 to 100, four rats treated with insulin from day 60 to 100 and two control rats. The rats were monitored from day 36 to 90 . As shown in Fig. 2, rats receiving insulin therapy have on average reduced blood glucose levels, but their levels did not drop below the $2.1 \mathrm{mmol} / \mathrm{l}$.

\section{Animals protected by long-term insulin treatment show a normal glucose tolerance and have no signs of insulitis at 160 days of age}

At 160 days of age, four of the non-diabetic long-term insulin treated rats, one non-diabetic control rat and one diabetic rat were exposed to the glucose tolerance test as described in the Materials and methods section. As demonstrated in Fig. 3, the non-diabetic control rat showed a good glucose tolerance. Three of the four non-diabetic rats from the long-term insulin treated group showed a comparable glucose tolerance. However, one rat of this group showed a reduced glucose tolerance. The diabetic rat displayed no glucose tolerance.

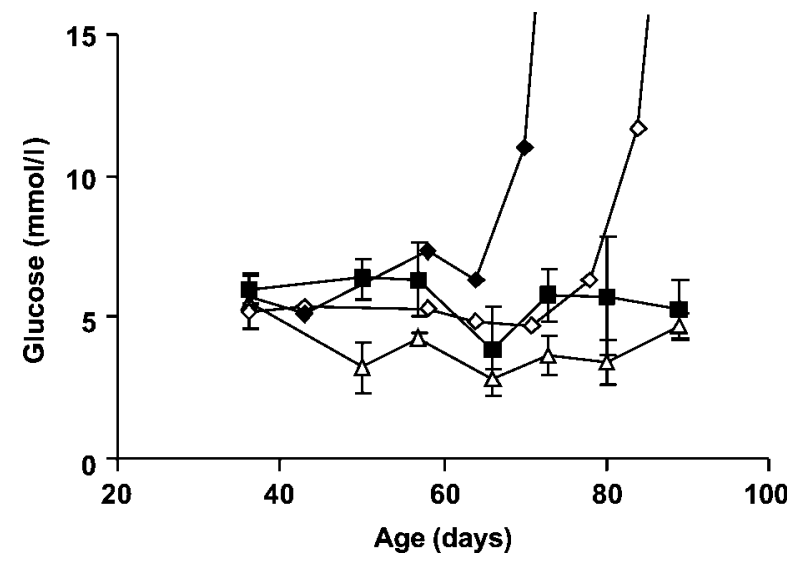

Figure 2 Animals under prophylactic insulin therapy display reduced blood glucose levels, but no severe hypoglycemia. DP-BB rats were treated with bovine insulin pellets (implanted s.c., release $1.5-2 \mathrm{IU} / 24 \mathrm{~h}$ for 40 days) from 21 to 100 days of age $(\triangle ; n=4)$ and from 60 to 100 days of age $(\mathbf{\square} ; n=4)$. The diabetes development was compared with two control rats $(\diamond$ and $\diamond$ ) which received a placebo pellet.

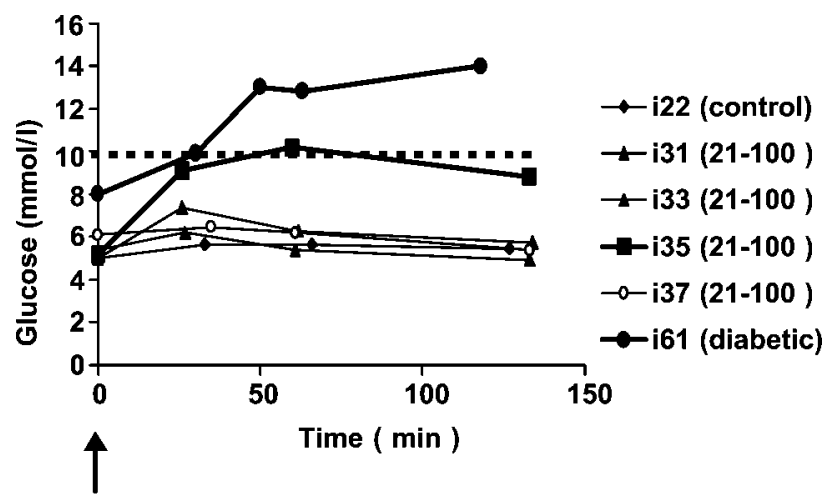

Glucose: $100 \mathrm{mg} / 100 \mathrm{~g}$ body-weight (i.p.)

Figure 3 Glucose tolerance of the prophylactic insulin treated rats. At 160 days of age, four of the non-diabetic long-term insulin treated rats, one non-diabetic control rat and one diabetic rat were exposed to the glucose tolerance test as described in the Materials and methods section. Three of the four non-diabetic 21-100 day treated rats showed a glucose tolerance comparable with the control rat. Although one rat showed a reduced glucose tolerance, it did not exceed the $11 \mathrm{mmol} / \mathrm{l}$ like the diabetic rat which showed no glucose tolerance.

At 160 days of age, the experiment was ended. The pancreas was removed from the non-diabetic rats and studied for histological signs of insulitis. As demonstrated in Table 1, the non-diabetic rats of the longterm treated group showed almost no signs of insulitis. The insulitis score of these rats was only slightly higher than the insulitis score detected in 56-day-old non-diabetic DP-BB rats or DR-BB rats.

Interestingly, the two remaining non-diabetic rats of the short-term treated group showed increased signs of insulitis as compared with the non-diabetic rats of the other groups.

\section{Long-term prophylactic insulin treatment reduces serum levels of anti-colloid autoantibodies in the DP-BB rat}

Besides the effect of the insulin treatment on diabetes development we also studied the effect of the prophylactic insulin treatment on the development of thyroiditis. In DP-BB rats thyroiditis development is associated with diabetes development (1). We measured the levels of anti-colloid autoantibodies in the serum of DP-BB rats older than 80 days that received insulin from day 21 to 100 and from day 60 to 100 . We compared these levels with untreated DP-BB rats over 80 days of age.

As shown in Table 2, the DP-BB rats treated with insulin from day 21 to 100 have reduced levels of anti-colloid autoantibodies in their serum as compared with the untreated DP-BB rats and the DP-BB rats that received insulin from day 60 to $100(P<0.05$, MannWhitney U test). From the long-term treated rats, only four of the nine rats showed detectable levels of anticolloid antibodies. Moreover, in these rats the autoantibodies were only detectable in the undiluted samples, 
Table 1 Histological insulitis score and number of islets per pancreas section of the diabetic and non-diabetic BB rats in the different treatment groups. The data are expressed as means \pm S.D.

\begin{tabular}{|c|c|c|c|c|}
\hline \multirow[b]{2}{*}{ Treatment $(n)$} & \multicolumn{2}{|c|}{ Diabetic } & \multicolumn{2}{|c|}{ Non-diabetic at 160 days of age } \\
\hline & Insulitis score $(n)$ & Number of islets & Insulitis score $(n)$ & Number of islets \\
\hline Control (23) & $2.73 \pm 0.68(18)$ & $6.75 \pm 2.79$ & $1.41 \pm 0.68(5)$ & $12 \pm 4.95$ \\
\hline Insulin day $21-60(11)$ & nd (9) & - & $1.96 \pm 0.02(2)^{\star}$ & $10 \pm 1.41^{* *}$ \\
\hline Insulin day $21-100(23)$ & $2.48 \pm 0.36(11)$ & $6.60 \pm 1.67$ & $1.19 \pm 0.15(12)^{\star \star \star}$ & $14.92 \pm 4.35$ \\
\hline Healthy 56-day-old DP-BB (3) & - & - & $1.02 \pm 0.03(3)$ & $18.33 \pm 1.53^{\#}$ \\
\hline
\end{tabular}

Table 2 Presence of anti-colloid antibodies in serum of DP-BB rats after prophylactic insulin treatment. Titers are expressed as means \pm S.D.

\begin{tabular}{|c|c|c|c|c|c|c|c|}
\hline & \multicolumn{6}{|c|}{ Dilution of serum } & \multirow[b]{2}{*}{ Titer } \\
\hline & Undiluted & $5 \times$ & $10 x$ & $20 x$ & $50 x$ & $100 x$ & \\
\hline \multicolumn{8}{|c|}{ DP-BB rats $>80$ days of age (control group) } \\
\hline $1(100)^{\#}$ & +++ & nd & ++ & ++ & + & - & 50 \\
\hline $2(105)^{\#}$ & + & - & - & - & - & - & 1 \\
\hline $3(99)^{\#}$ & + & - & - & - & - & - & 1 \\
\hline $4(98)^{\#}$ & + & - & - & - & - & - & 1 \\
\hline $5(100)^{\#}$ & + & - & - & - & - & - & 1 \\
\hline $6(100)^{\#}$ & + & + & - & - & - & - & 1 \\
\hline $7(130)$ & + & nd & - & - & - & - & 1 \\
\hline $8(130)$ & + & nd & + & - & - & - & 10 \\
\hline $9(130)$ & +++ & nd & + & + & - & - & 20 \\
\hline $10(130)$ & ++ & nd & + & + & - & - & $\begin{array}{l}20 \\
11+5\end{array}$ \\
\hline \multirow{2}{*}{\multicolumn{8}{|c|}{ DP-BB rats treated with insulin from 60 to 100 days of age }} \\
\hline $11(100)^{\#}$ & +++ & +++ & & & & & \\
\hline $12(97)^{\#}$ & ++ & + & - & - & - & - & 5 \\
\hline $13(104)^{\#}$ & +++ & +++ & ++ & + & + & + & 100 \\
\hline $14(160)^{\#}$ & - & - & - & - & - & - & 0 \\
\hline $15(180)$ & + & + & - & - & - & - & 5 \\
\hline $16(139)^{\#}$ & - & - & - & - & - & - & 0 \\
\hline $17(180)$ & + & + & - & - & - & - & 5 \\
\hline $18(130)^{\#}$ & ++ & + & + & - & - & - & 10 \\
\hline $19(160)$ & +++ & +++ & ++ & + & + & - & 50 \\
\hline $20(160)$ & + & - & - & - & - & - & 1 \\
\hline $21(100)^{\#}$ & + & - & - & - & - & - & 1 \\
\hline $22(98)^{\#}$ & + & - & - & - & - & - & 1 \\
\hline Mean & & & & & & & $23 \pm 11$ \\
\hline \multicolumn{8}{|c|}{ DP-BB rats treated with insulin from 21 to 100 days of age } \\
\hline $23(191)$ & - & - & - & - & - & - & 0 \\
\hline $24(121)^{\#}$ & - & - & - & - & - & - & 0 \\
\hline $25(191)$ & - & - & - & - & - & - & 0 \\
\hline $26(191)$ & - & - & - & - & - & - & 0 \\
\hline $27(100)^{\#}$ & + & - & - & - & - & - & 1 \\
\hline $28(191)$ & + & - & - & - & - & - & 1 \\
\hline $29(114)^{\#}$ & + & - & - & - & - & - & 1 \\
\hline $30(100)^{\#}$ & + & - & - & - & - & - & 1 \\
\hline $31(100)^{\#}$ & + & - & - & - & - & - & 1 \\
\hline Mean & & & & & & & $0.6 \pm 0.2$ \\
\hline
\end{tabular}

${ }^{*} P<0.05$ as compared with the control group and the rats treated with insulin from day 60 to 100 . The control group does not differ from the $60-100$ day insulin treated group.

+++ , very strong positive; ++ , strong positive; + , positive; - , negative. \#Diabetic rat. while in the other groups, some individual rats had detectable autoantibodies in 100-fold diluted serum.

As is shown in Table 2, the diabetic animals did not display higher titers of anti-colloid autoantibodies than the non-diabetic animals.

\section{Discussion}

In this paper it is demonstrated that a short-term insulin treatment between 21 and 60 days of age does not influence diabetes development in the DP-BB rat. However, long-term insulin treatment from day 21 to 100 gave a reduction of approximately $42 \%$ in diabetes incidence at 160 days of age. Accordingly, protected longterm treated rats showed normal glucose tolerance and minimal to no signs of insulitis. Interestingly, long-term treated rats showed reduced serum levels of anti-colloid autoantibodies as compared with the control rats.

What might be the mechanisms involved in the antidiabetogenic effect of the long-term prophylactic insulin treatment? Previous research has indicated that for this anti-diabetogenic effect, the activity of the $\beta$-cell is very important. For instance, Janssen et al. (10) demonstrated in the NOD mouse model of diabetes that induction of $\beta$-cell rest by prophylactic insulin treatment reduces the infiltration of destructive macrophages into the islets of Langerhans. It is thought that this influx of macrophages and or dendritic cells is a normal phenomenon and the $\beta$-cell needs to be nurtured by these cells (H Drexhage, Erasmus University, The Netherlands, personal communication). Production of chemokines like MCP-1 may be involved in this process, because it has been shown that active $\beta$-cells can produce MCP-1 (17-19). This production of MCP-1 and other chemokines can be increased by exposure of the $\beta$-cells to inflammatory cytokines like IL-1 and TNF- $\alpha$ (17-19). Therefore, it is acceptable to hypothesize that when the $\beta$-cells are kept quiet by exogenous insulin, they might produce less or no chemokines, and the macrophages, dendritic cells and $\mathrm{T}$ cells will not be attracted to the islets of Langerhans. 
Interestingly, insulin itself has anti-inflammatory properties. It was demonstrated that insulin could suppress the induction of the transcription factor $\mathrm{NF} \kappa \mathrm{B}$ that is important for the induction of proinflammatory cytokines and chemokines $(20,21)$. Moreover, insulin was demonstrated to suppress the production of MCP-1 (22).

Another mechanism might be the fact that insulin treatment makes the $\beta$-cells less immunogenic, as was demonstrated by Anastasi et al. (23). Accordingly, Aaen et al. (24) showed that $\beta$-cells activated in vitro by high glucose levels express higher densities of $\beta$-cell associated antigens.

Induction of tolerance to insulin is thought not to be dominantly involved in parental prophylactic insulin treatment, but to be the key mechanism in the prevention of diabetes by oral insulin therapy (9).

In our experiments the rats on insulin therapy showed on average a reduced blood glucose level. This indicates that the $\beta$-cells of these rats were less activated by glucose. Therefore, in our experiments the dominant protective mechanism might be induction of $\beta$-cell rest, but the other protective mechanisms as described above may be involved as well.

Besides diabetes, DP-BB rats also develop thyroiditis (25). When DP-BB rats are over 90 days of age, they start to show histological signs of thyroiditis (25). However, at that age most of the DP-BB rats have developed diabetes. Diabetes development in DP-BB rats is very acute and the rats can die of hyperglycemia in a few days. Therefore, the rats must be monitored at least three or four times a week to prevent unnecessary deaths by hyperglycemia. To study thyroiditis development in DP-BB rats, most researchers treat the DP-BB rats with insulin at the moment of diabetes onset (25).

We have demonstrated in this paper that DP-BB rats can be treated with insulin-releasing pellets just before they start to develop diabetes (at 60 days of age), without affecting the levels of anti-colloid autoantibodies. Unfortunately, we could not correlate the titers of anti-colloid autoantibodies with histological signs of thyroiditis. DP-BB rats mainly develop histological signs of thyroiditis when they are put on an iodineenriched diet. Since our rats were kept on standard diets, they did not develop histological signs of thyroiditis. However, rats kept on standard diets can still show elevated titers of anti-colloid autoantibodies (26). Because expression of anti-colloid autoantibodies is strongly associated with thyroiditis development (25), it is acceptable to hypothesize that treatment with insulin from 60 days of age has no effect on thyroiditis development. The fact that we found histological signs of thyroiditis in a 100-day-old DP-BB rat treated with insulin from day 60 to 100 (rat 11, Table 2) supports this hypothesis. However, treating the rats with insulin from day 21 to 100 gives a reduction of serum anti-colloid autoantibody levels. Therefore we state that long-term treatment with insulin might influence the development of thyroiditis in the DP-BB rat.
Taken together, diabetes development in humans and the DP-BB rat is multifactorial. The immune system, $\beta$-cell functionality, viral infections and diabetogenic food antigens are the key players in diabetes development (1-4). This multifactoriality can explain why the timing and duration of the insulin treatment has differential effects on the diabetes development in the DP-BB rat. We have demonstrated that short-term insulin treatment in the diabetes-sensitive period between 21 and 60 days is not sufficient to prevent diabetes in the DP-BB rat. The prophylactic insulin treatment has to start well before the onset of diabetes development and be prolonged into the phase when the rats normally become diabetic.

Finally, these results show that with regard to the human situation, treatment with insulin has therapeutic potential. However, recent clinical trials showed that prophylactic insulin therapy in firstdegree relatives of type 1 diabetics could not prevent diabetes development (27). In these trials, low-dose insulin treatment was used (27). In our animal model and the other animal models high-dose insulin therapy is used (9). In view of our results, employing high-dose prophylactic insulin therapy in children at risk for developing diabetes might be promising. However, high-dose insulin therapy may have severe side-effects like hypoglycemia and subsequently reduced cognitive functions (27). Therefore, optimal dose and safety has to be established before employing high-dose prophylactic insulin therapy.

\section{Acknowledgements}

This study was supported by research grants 96.066 (HG) and 98.148 (JV) from the Dutch Diabetes Foundation.

\section{References}

1 Mordes JP, Bortell R, Groen H, Guberski DL, Rossini AA \& Greiner D. Autoimmune diabetes mellitus in the BB rat. In Animal Models for Autoimmune diseases, pp 1-41. Eds AAF Sima \& E Shafrir. Amsterdam: Harwood Academic Publishers, 2001.

2 Knip M \& Akerblom HK. Environmental factors in the pathogenesis of type 1 diabetes mellitus. Experimental Clinical Endocrinology and Diabetes 1999107 S93-S100.

3 Akerblom HK \& Knip M. Putative environmental factors in type 1 diabetes. Diabetes/Metabolism Reviews 199814 31-67.

4 Visser J, Klatter F, Vis L, Groen H, Strubbe J \& Rozing J. Short-term dietary adjustment with a hydrolyzed casein based postpones diabetes development in the diabetes prone BB rat. Metabolism: Clinical and Experimental 200353 333-337.

5 Saldeen J. Cytokines induce both necrosis and apoptosis via a common Bcl-2-inhibitable pathway in rat insulin-producing cells. Endocrinology $20001412003-2010$.

6 Rabinovitch A. An update on cytokines in the pathogenesis of insulin-dependent diabetes mellitus. Diabetes/Metabolism Reviews $199814129-151$.

7 Rabinovitch A, Suarez-Pinzon W, El Sheikh A, Sorensen O \& Power RF. Cytokine gene expression in pancreatic islet-infiltrating leukocytes of BB rats: expression of Th1 cytokines correlates with 
beta-cell destructive insulitis and IDDM. Diabetes $1996 \mathbf{4 5}$ $749-754$.

8 Kolb H, Worz-Pagenstert U, Kleemann R, Rothe H, Rowsell P \& Scott FW. Cytokine gene expression in the BB rat pancreas: natural course and impact of bacterial vaccines. Diabetologia 199639 $1448-1454$.

9 Gottlieb PA \& Eisenbarth GS. Insulin-specific tolerance in diabetes. Clinical Immunology $2002 \mathbf{1 0 2} 2-11$.

10 Jansen A, Rosmalen JG, Homo-Delarche F, Dardenne M \& Drexhage HA. Effect of prophylactic insulin treatment on the number of ER-MP23 + macrophages in the pancreas of NOD mice. Is the prevention of diabetes based on beta-cell rest? Journal of Immunity 19969 341-348.

11 Gotfredsen CF, Buschard K \& Frandsen EK. Reduction of diabetes incidence of BB Wistar rats by early prophylactic insulin treatment of diabetes-prone animals. Diabetologia 198528 933-935.

12 Gottlieb PA, Handler ES, Appel MC, Greiner DL, Mordes JP \& Rossini AA. Insulin treatment prevents diabetes mellitus but not thyroiditis in RT6-depleted diabetes resistant BB rats. Diabetologia $199134296-300$

13 Like AA, Kislauskis E, Williams RM, Williams RR \& Rossini AA Neonatal thymectomy prevents spontaneous diabetes mellitus in the BB/W rat. Science 1982216 644-646.

14 Burstein D, Mordes JP, Greiner W, Stein D, Nakamura N, Handler ES et al. Prevention of diabetes in BB/Wor rat by single transfusion of spleen cells. Parameters that affect degree of protection. Diabetes 198938 24-30.

15 Visser J, Groen H, Klatter F \& Rozing J. Timing of pentoxifylline treatment determines its protective effect on diabetes development in the Bio Breeding rat. European Journal of Pharmacology 2002 $445133-140$.

16 Garofano A, Czernichow P \& Breant B. Beta-cell mass and proliferation following late fetal and early postnatal malnutrition in the rat. Diabetologia 199841 1114-1120.

17 Chen MC, Proost P, Gysemans C, Mathieu C \& Eizerik DL. Monocyte chemoattractant protein-1 is expressed in pancreatic islets from prediabetic NOD mice and in interleukin-1 betaexposed human and rat islet cells. Diabetologia $2001 \mathbf{4 4}$ $325-332$.
18 Piemonti L, Leone BE, Nano R, Saccani A, Monti P, Maffi P et al. Human pancreatic islets produce and secrete MCP-1/CCL2: elevance in human islet transplantation. Diabetes 200251 $55-65$.

19 Frigerio S, Junt T, Lu B, Gerard C, Zumsteg U, Hollander GA et al. $\beta$-cells are responsible for CXCR3-mediated T-cell infiltration in insulitis. Nature Medicine 20028 1414-1420.

20 Luster AD. Chemokines - chemotactic cytokines that mediate inflammation. New England Journal of Medicine $1998 \mathbf{3 3 8}$ $436-445$.

21 Dandona P, Aljada A, Mohanty P, Ghanim H, Hamouda W, Assian E et al. Insulin inhibits intranuclear nuclear factor kappaB and stimulates IkappaB in mononuclear cells in obese subjects: evidence for an anti-inflammatory effect? Journal of Clinical Endocrinology and Metabolism 200186 3257-3265.

22 Dandona P, Aljada A \& Mohanty P. The anti-inflammatory and potential anti-atherogenic effect of insulin: a new paradigm. Diabetologia 200245 924-930.

23 Anastasi E, Dotta F, Tiberti C, Vecci E, Ponte E \& Di Mario U. Insulin prophylaxis down-regulates islet antigen expression and islet autoimmunity in the low-dose Stz mouse model of diabetes. Autoimmunity 199929 249-256.

24 Aaen K, Rygaard J. Josefsen K, Petersen H, Brogren CH, Horn T et al. Dependence of antigen expression on functional state of beta-cells. Diabetes $199039697-701$.

25 Delemarre FG, Simons PJ \& Drexhage HA. The BB rat as a model for autoimmune thyroiditis: relevance for the pathogenesis of human disease. Experimental and Clinical Endocrinology and Diabetes $1996 \mathbf{1 0 4} 10-12$.

26 Mooij P. The thyroid, iodine and autoimmunity. $\mathrm{PhD}$ Thesis University of Rotterdam, The Netherlands, 1993.

27 Diabetes Prevention Trial - Type 1 Diabetes Study Group. Effects of insulin in relatives of patients with type 1 diabetes mellitus. New England Journal of Medicine 2002346 1685-1691.

Received 17 February 2003

Accepted 3 June 2003 